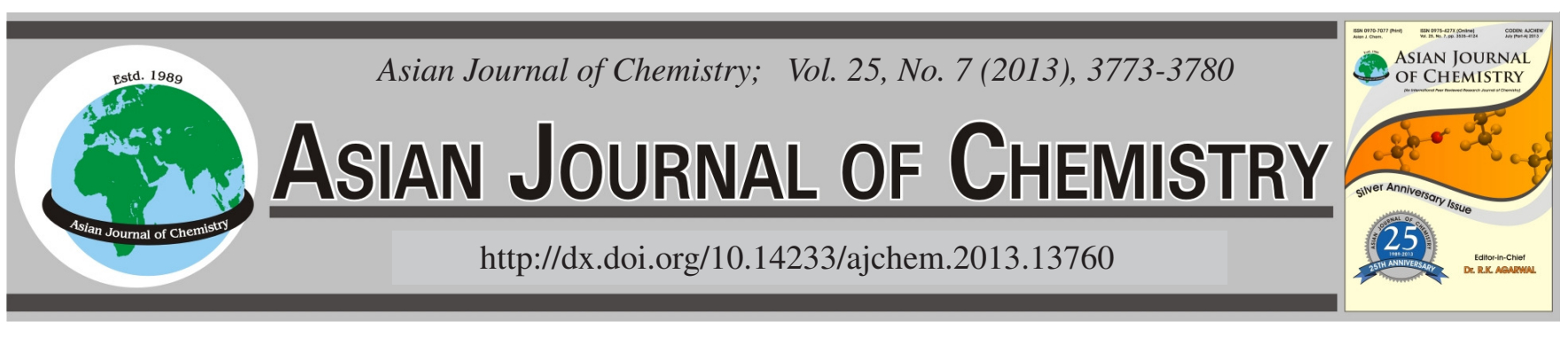

\title{
Characterization of Aromatic Hydrocarbons in Tropical Coastal Water of Sabah, Borneo
}

\author{
Kogila Vani Annammala ${ }^{1, *}$, Mohd Harun Abdullah ${ }^{1}$, Mazlin Bin Mokhtar ${ }^{2}$, Collin G. Joseph ${ }^{3}$ and Mahyar Sakari ${ }^{1}$
}

${ }^{1}$ Environmental Science Programme, School of Science and Technology, Universiti Malaysia Sabah, Locked Bag 2073, 88999 Kota Kinabalu, Sabah, Malaysia

${ }^{2}$ Institute for Environment and Development (LESTARI), Universiti Kebangsaan Malaysia, Selangor, 43600 UKM Bangi, Selangor, Malaysia ${ }^{3}$ Industrial Chemistry Programme, School of Science and Technology, Universiti Malaysia Sabah. Locked Bag 2073, 88999 Kota Kinabalu, Sabah, Malaysia

*Corresponding author: Fax: +6 088247 820; Tel: +6 088320000 ext 5720; E-mail: a.kogilavani@ gmail.com

Key Words: Oil and Grease, Polyaromatic hydrocarbons.

\section{INTRODUCTION}

Coastal environment is a vast sparsely populated wilderness. These environments are susceptible to man-induced stresses, such as pollution and climate changes. Prodigious amount of crude oil are extracted from earth every year and moved across the oceans and approximately $0.1 \%$ of the total oil extracted ends up in the marine systems each year, with accidental spills having the most spectacular impact. Petroleum hydrocarbons also enter the coastal marine environment as exhaust particulates, fuel spills, urban runoffs contaminated with crankcase oil and the by-products of biomass combustion ${ }^{1,2}$. Low molecular weight hydrocarbons tend to be more concentrated in the vapour-phase while the ones with higher molecular weight are often associated with particulates ${ }^{3,4}$.

There are more than 600 different types of hydrocarbons reported from petroleum products in which aromatics are the second largest group ${ }^{5,6}$. Polycyclic aromatic hydrocarbons (PAHs) are mainly concerned pollutants in the environment due to their toxic, mutagenic and carcinogenic properties ${ }^{7-9}$. United states environmental protection agency (USEPA) listed 16 of polycyclic aromatic hydrocarbons as priority pollutant compounds for human and the environment ${ }^{10-12}$. This paper examines the environmental protection agency lists of the 16 polycyclic aromatic hydrocarbons hazardous compounds, which are further divided into carcinogenic and non-carcinogenic polycyclic aromatic hydrocarbons. The two and three ring polycyclic aromatic hydrocarbons are non-carcinogenic, while several four, five and six membered rings of polycyclic aromatic hydrocarbons are carcinogenic. The four membered ring polycyclic aromatic hydrocarbons are chrysene and benzo (a) anthracene. The five membered ring polycyclic aromatic hydrocarbons are benzo(a)pyrene, benzo(b)fluoranthene, benzo(k)fluoranthene and dibenzo(a,h)anthracene. Six mem- 
bered rings carcinogenic polycyclic aromatic hydrocarbon include indeno(1,2,3-cd)pyrene. Benzo(a)pyrene is the most potent carcinogenic among the polycyclic aromatic hydrocarbons ${ }^{13}$. Regulatory concerns are generally focused on benzo(a)pyrene, total carcinogenic polycyclic aromatic hydrocarbons ( $\Sigma$ PAHs) and total polycyclic aromatic hydrocarbons ( $\Sigma$ PAHs), which is the main focus in this study. Benzo (a) pyrene appears to exhibit low acute toxicity but have very significant chronic toxicity. Single dose will not cause immediate adverse effects but continuous low doses will probably induce cancer ${ }^{14-18}$.

The international agency for research on cancer (IARC) has characterized polycyclic aromatic hydrocarbon as carcinogens and classified polycyclic aromatic hydrocarbons into three main groups which are Group 2A, Group 2B and Group 3. Group 2A characterizes polycyclic aromatic hydrocarbons that have probably carcinogenic impact to humans; benzo(a)anthracene, benzo(a)pyrene, dibenzo(a,h)anthracene. Group $2 \mathrm{~B}$ is defined as possibly carcinogenic to humans, with maximum acceptable concentration of $200 \mathrm{ng} / \mathrm{L}^{19}$. polycyclic aromatic hydrocarbons that fall in this group are fluorine, Benzo (b) fluoranthene, benzo (k) fluoranthene, Idenol $(1,2,3 c d)$ pyrene, finally group 3 , unclassifiable with respect to carcinogenicity in humans; phenanthrene, anthracene, fluoranthene, pyrene, chrysene, benzo(g,h,i)prylene ${ }^{17,20,21}$. Existence of all these compounds exceeding $20 \mathrm{ng} / \mathrm{L}$ in the marine environment causes many problems both to the environment and the organisms inhibiting in the ecosystem ${ }^{22}$.

According to the data provided by Malaysian Department of Environment, Malaysia has a coastline measuring 4,675 $\mathrm{km}$, inclusive of Peninsular Malaysia and the states of Sabah and Sarawak, endowing more than 100 coastal islands whose marine environments are generally rich in natural resources ${ }^{23}$. This paper provides a summary on the levels of oil and grease and polycyclic aromatic hydrocarbons, in the tropical coastal waters of Sabah, on the island of Borneo. A total of four sites were chosen for this study which includes three small islands in the Tunku Abdul Rahman Park namely; Manukan, Mamutik and Sapi Island and Kota Kinabalu main port (also known as Jesselton port).

As mentioned, polycyclic aromatic hydrocarbons been reported to have implications for human and ecosystem health, analysis of spatial and temporal trends in this field are lacking specifically in Sabah coastal area. Soh and Abdullah ${ }^{24}$ and Isobe et $a l .{ }^{25}$ studied the polycyclic aromatic hydrocarbons in Malaysian mussels reported that their study areas were all heavily polluted by petrogenic polycyclic aromatic hydrocarbons. The location for Soh and Abdullah ${ }^{24}$, research in Sabah was close to an oil platform, therefore the source of contamination was most likely from crude oil in the area. Since oil platforms were nowhere near this current study site, focus were on the detecting the presence of the contaminant, level of contamination and to suggest related actions to be taken accordingly if necessary based on the significance of the concentration level. Sabah's coastal and marine environment contains many species, habitat for diverse marine flora and fauna and other resources that could be greatly affected by oil pollution.

Tourism assists in the conservation of the environment, but has in some cases through improper management caused stress or destruction to the natural environment eg. Sipadan Island, Sabah. Jakobsen etc. ${ }^{26}$ mentioned that coral reefs in Sabah have been rapidly and adversely impacted by human activities for decades. Further, he reported that some of the affected area includes protected islands as the Tunku Abdul Rahman Parks, which consists of 3 main islands namely Manukan, Mamutik and Sapi. This research documents the level of oil and grease and polycyclic aromatic hydrocarbons in the waters and sediments of the coast of the selected locations. Through a pilot study, the major source of monitored contaminants was from local boats transporting tourists and visitors to the islands. The only source of contaminant in terminals and main Kota Kinabalu Port was ferries and ships that calls at harbour. Since boating is still the main and the only transportation to and fro the islands, the study was initially focused on oil and grease contamination and identification of polycyclic aromatic hydrocarbons molecular markers. This is to detect possible contamination from incomplete combustions and leakage related to boating activities. Active oil explorations, drillings and operations were not present at the sampling stations and the presence of tar-balls was also not detected.

\section{EXPERIMENTAL}

Sampling: For oil and grease analysis, samples were collected using $1 \mathrm{~L}$ glass bottles with PTFE-lined screw caps. All samples were refrigerated and stored at $4{ }^{\circ} \mathrm{C}^{27}$. Samples for Polycyclic aromatic hydrocarbons were collected using Amber glass with Teflon-lined caps which were cleaned according to environmental protection agency specifications, samples were preserved by refrigerating at $4{ }^{\circ} \mathrm{C}$, the liquids samples were extracted within 7 days and the extracts were analyzed within 40 days of sampling. Liquid aqueous samples were preserved in acidic condition $(\mathrm{pH}<2)^{28,29}$.

Oil and grease analysis: Environmental protection agency method 1664 was adopted for the analysis of oil aqueous whereas partition-gravimetric method was used to determine the concentration of oil and grease in the laboratory. The method is based on environmental protection agency (EPA), which is also the current method being used in environmental protection agency's survey and monitoring programs under the clean water act. This method is applied to determine the $n$-hexane extractable material (HEM) and $n$-hexane extractable material that is not absorbed by silica gel (SGT-HEM) in surface and saline waters and industrial and domestic aqueous water. The extractable materials that may be determined in this method are relatively non-volatile hydrocarbons, vegetable oils, animal fats, waxes, soaps, gasses and related materials ${ }^{30,31}$. Oil and grease is a conventional pollutant defined in the act and is codified at CFR 401.16 $6^{32}$.

Precision and recovery (PAR) standard was prepared with a mixture of hexadecane/stearic acid (1:1) also known as spiking solution which was prepared acetone at a concentration of $4 \mathrm{mg} / \mathrm{mL}$ each. The solution was prepared by mixing $400 \pm$ $4 \mathrm{mg}$ stearic acid and $400 \pm 4 \mathrm{mg}$ hexadecane in a $100 \mathrm{~mL}$ volumetric flask. The final weight prepared should be $40 \pm 1$ $\mathrm{mg}$, the concentration was checked by removing $5.00 \pm 0.05$ $\mathrm{mL}$ with a volumetric pipette placed on a tared weighing pan and evaporated to dryness in a fume hood. This precision and recovery standard is used for determination of initial precision 
and recovery and ongoing precision and recovery procedure. This spiking solution was frequently checked for any signs of degradation or evaporation and was replaced after 6 months or earlier if degradation was observed.

After verifying that the $\mathrm{pH}$ of each sample was less than 2 , the sample was prepared for extraction. Sample was poured into a separatory funnel with $30 \mathrm{~mL}$ of $n$-hexane added to the sample and shaken well. Then the organic phase was allowed to separate from aqueous phase for about $10 \mathrm{~min}$ before draining the aqueous layer back to the original sample container. The solvent was evaporated by immersing the lower end of the flask in a water bath at adjusted temperature of $70{ }^{\circ} \mathrm{C}$. The flasks are then cooled in the desiccators; the outside surface was wiped to remove moisture and fingerprints prior to be weighed.

Polycyclic aromatic hydrocarbons detection by using GC-MS: The standard operating procedure (SOP) followed in this study is based on the guidance as mentioned in environmental protection agency Method 625 for analyzing base/ neutral and acid extractable compounds. Prior to analysis, $1 \mathrm{~mL}$ of surrogate standard solution was added to both blank and matrix spike just prior to extraction and $\mathrm{pH}$ adjustment. Then internal standard were added to all samples and standards to allow internal standard quantification, the function of internal standard is to compensate analytical results for losses or instrument biases over the full range GC retention times. Approximately $1 \mathrm{~L}$ aliquot sample was spiked with surrogate and serially extracted three times with $60 \mathrm{~mL}$ each of methylene chloride in a $1 \mathrm{~L}$ separatory funnel. Water was removed from the extract with anhydrous sodium sulphate. The dry extract was then concentrated in volume to 1.0 to $2.0 \mathrm{~mL}$ with a Kuderna-Danish concentrator and nitrogen blown-down apparatus. The extract is exchanged into a specified solvent with final analytical method.

The GC-MS used in this study is Hewlett-Packard Model 5980 (A or Series II) which was fitted with auto-sampler. The column used for the Base/neutral species was a glass column which is $1.8 \mathrm{~m}$ long by $2 \mathrm{~mm}$ I.D packed with $3 \%$ SP-2250 on Supelco port (100/120). Meanwhile for the acid species the column used was a glass column which is $1.8 \mathrm{~m}$ long by $2 \mathrm{~mm}$ I.D. with $1 \%$ SP-1240 DA on Supelco port (100/120 mesh). The mass spectrometer used had a mass selective detector that was able to scan the mass range of 35 to $450 \mathrm{amu}$ every $7 \mathrm{sec}$ with an ionizing potential of 70 volts in the electron impact ionization mode. The detector and associated electronic and software can produce a mass spectrum of decafluorotriphenylphosphine (DFTPP) after a $1 \mu \mathrm{L}$ injection of GC/MS tuning standard.

\section{RESULTS AND DISCUSSION}

The highest level of oil and grease contamination detected was in Port Kota Kinabalu, $40.62 \mathrm{mg} / \mathrm{L}$, followed by $23.2 \mathrm{mg} / \mathrm{L}$ in Manukan Island. The port contained the highest oil and grease pollution during the December sampling, similar to results obtained by Abdullah $^{24}$, but in a different location in Peninsular Malaysia. This was due to active shipping activity and offloading operations. It has been observed that the concentrations of oil and grease are influenced by several factors such as the type of oil, quantity, weathered state of the oil and also by the prevailing climatic and tidal conditions ${ }^{28,33}$. This explains the drastic increased in the concentration of oil and grease in most stations when repetition sampling was performed in February. The readings are comparatively higher due to the tidal effect. According to the Marine Department of Sabah, December sampling during the high tide period and February was lower tide. Except in Port where significance decrease was observed $(8.53 \mathrm{mg} / \mathrm{L})$, according to Tam et $_{\text {al. }}{ }^{28}$, and Liu et $a l .{ }^{33}$, mentioned that the presence of plants and debris in the water body may trap the oil silts together. This explains the low concentrations of oil and grease detected in the Port during the second sampling. During first sampling, the location was free from rubbish and plants and was active in shipping activities compared to the second sampling where the water was covered with silt, rubbish and organic matters such as leaf, tree branches and debris (Fig. 1).

In Manukan Island when significant increase in oil and grease was observed in February (130.23 mg/L), similar drastic increased in the nearest islands Sapi $(38.40 \mathrm{mg} / \mathrm{L})$ and Mamutik Island (46.05) $\mathrm{mg} / \mathrm{L}$ the same pattern was repeated in December which was 23.3, 8.2 and $13.6 \mathrm{mg} / \mathrm{L}$, respectively.
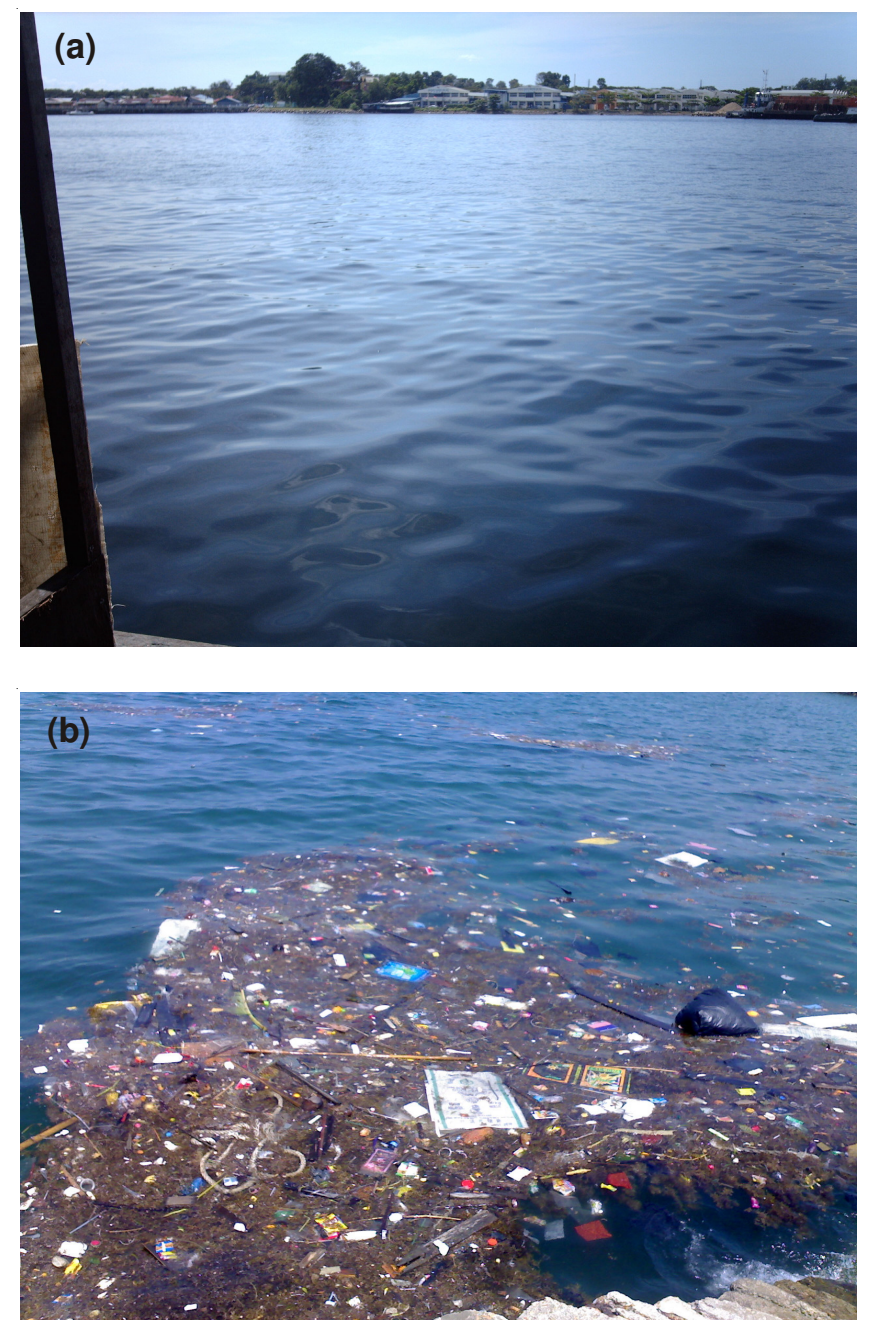

Fig. 1. Location at Port during first (a) and second sampling (b). During second sampling water was covered with silt, rubbish and organic matters

During the second sampling increase in boating, scuba diving, 
water related sports and a lot of visitors and tourists were noticed. Increase in activity linked in the increase in the level of oil and grease contamination. This finding was similar as reported by Tam et al. ${ }^{28}$. When correlation coefficient test among $\mathrm{pH}$ and temperature was performed the test produced the similar result as concluded by Burns and $\operatorname{Codi}^{34}$ and Lie et al. ${ }^{33}$. The analysis showed that the concentration of oil and grease concentration is positively related to the changes on $\mathrm{pH}$ and temperature. Further Burns and $\mathrm{Codi}^{34}$ and Liu et al..$^{33}$, reported on negatively significant correlation with tidal effects, which could not be achieved in this study as the data was considered as discrete. Fig. 2 shows the matrix plot relating the positive relationship with $\mathrm{pH}$ and temperature the other data is shown as discrete for tidal effects.
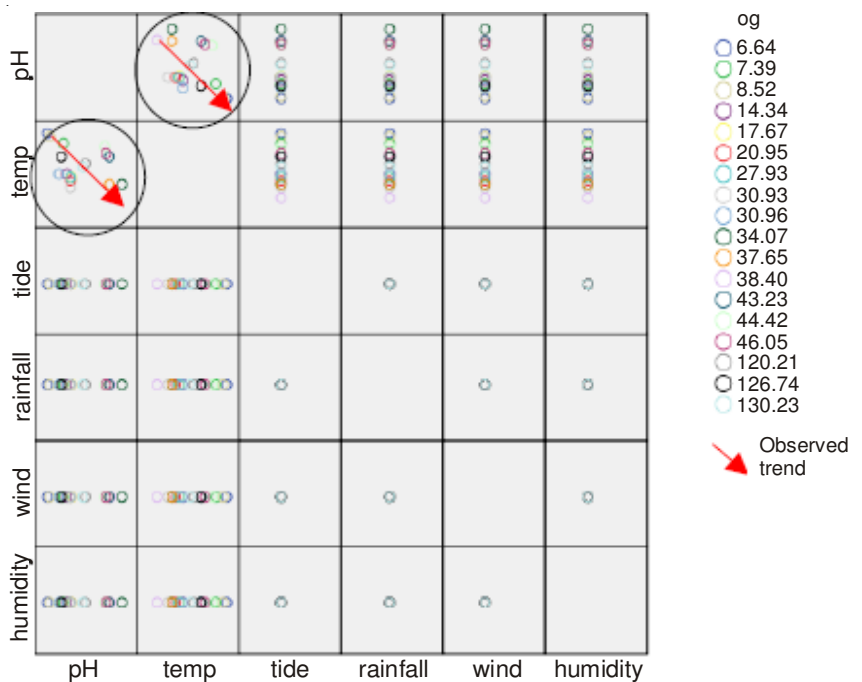

Fig. 2. Matrix plot on the relationship between oil and grease contamination and the in-situ parameters

According to the INWQS, 2003, water quality criteria for oil and grease, for aquatic life protection is $0.04 \mathrm{mg} / \mathrm{L}$. The obtained data showed relatively high level of oil and grease (Fig. 3). All of the reading obtained did not fulfil the water quality standard for oil and grease by the Malaysian interim water quality standard. Similar to report by the Department of Environment of Sabah, which mentioned that fall 130 monitoring stations all over Sabah exceeds the limit ${ }^{35}$.

Polycyclic aromatic hydrocarbons analysis: The worst environmental pollutants in the aquatic system are oily hydrocarbons especially aromatic and polyaromatic compounds ${ }^{22}$. The existence of oily compounds with an approximate concentration of $0.1 \mu \mathrm{g} / \mathrm{L}$ in aquatic environment prevents the growth of fish larva besides causing a generic state manner of animal. Analysis of the sediments in the sandy soil beach of the small islands was performed during high and low tide. Prior to the analysis, quality analysis and quality control analysis were conducted to ensure the quality of data produced. Among the quality analysis and quality control was calibration checks, method blank, matrix spikes, matrix spike duplicate and in some case sample duplicate, GC/MS tuning standard, initial calibration standards, continuing calibration standards (CCs), system performance check compounds (SPCCs), calibration

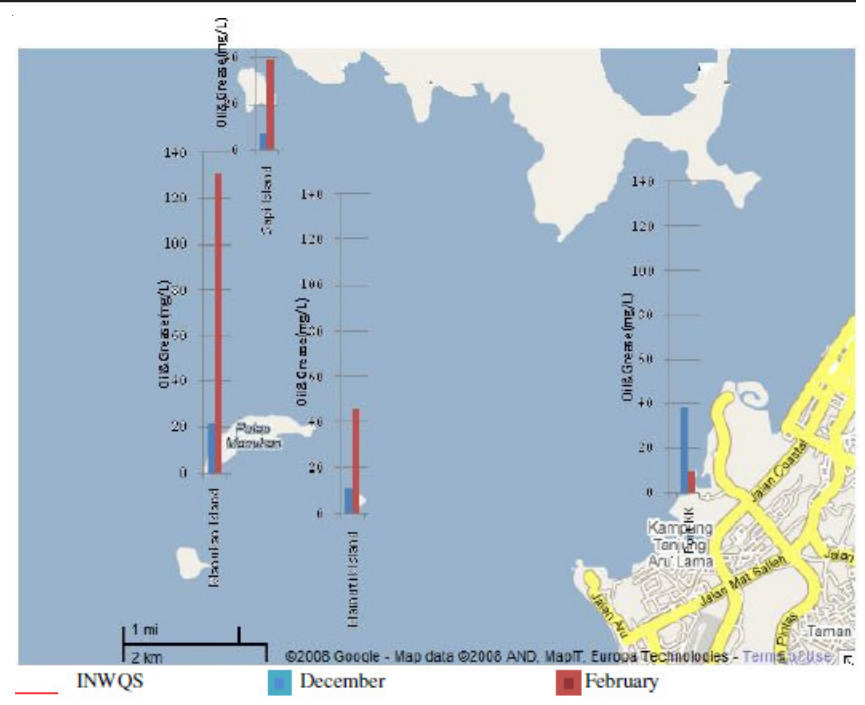

Fig. 3. Summary of oil and grease concentration is all stations

check compounds (CCCs) on system check up. Apart from that, daily calibration using DFTPP and auto tuning were performed prior beginning the analysis.

The procedural blanks did not show any polycyclic aromatic hydrocarbon contamination. The accuracy and reproducibility of the polycyclic aromatic hydrocarbon analytical method were satisfactory. The percentage recoveries of 16 polycyclic aromatic hydrocarbons from the certified reference standard (HS-6) ranged from 70 to $112 \%$. The results were comparable with those reported by previous works such as Nora et $a l .^{36}$, Zheng et $a .^{37}$, also fulfilled the acceptance criteria as guide lined by the environmental protection agency Methods (1983) and as suggested by Burns et al. ${ }^{38}$. As shown in Fig. 4, from the results of water samples from the small islands; total polycyclic aromatic hydrocarbons detected in Manukan, Sapi and Mamutik Islands are 1.12, 0.61 and 0.60 $\mu \mathrm{g} / \mathrm{mL}$. Naphthalene (Nap) was detected in all the three samples, ranging from $0.18 \mu \mathrm{g} / \mathrm{mL}$ to $0.20 \mu \mathrm{g} / \mathrm{mL}$ in Sapi island however Nap is not considered as a cancer causing substance ${ }^{39}$. Polycyclic aromatic hydrocarbons with four rings which are Pyrene (pyr), benzo (a) anthracene and chrysene, which are all classified as class $\mathrm{B}_{2}$ (probable human carcinogen) were detected to be present in trace amounts in all these three locations.

The detected concentration in each samples vary considerably from very low to below harmful limits. The concentrations determined from Manukan, Sapi and Manukan waters were $0.18,0.14$ and $0.16 \mu \mathrm{g} / \mathrm{mL}$ for pyrene, $0.7,0.08$ and 0.06 $\mu \mathrm{g} / \mathrm{mL}$ for benzo (a) anthracene and $0.06,0.08$ and $0.07 \mu \mathrm{g} / \mathrm{mL}$ for chrysene. Comparing the three islands during the December sampling, Manukan Island contained the highest amount of polycyclic aromatic hydrocarbons. Mostly four ring polycyclic aromatic hydrocarbons were detected present in each of the locations which are pyrene, benzo(a)anthracene and chrysene. Benzo(a)pyrene was also detected in trace amounts at all three locations. Total polycyclic aromatic hydrocarbons detected measures 0.10, 0.09 and $0.12 \mu \mathrm{g} / \mathrm{mL}$ respectively in Mamutik, Sapi and Manukan Island however all were below the permissible polluted level (below 20-50 ng/L). Environmental protection agency's carcinogenicity risk assessment verification endeavour work group has classified benzo(a)pyrene as carcino- 


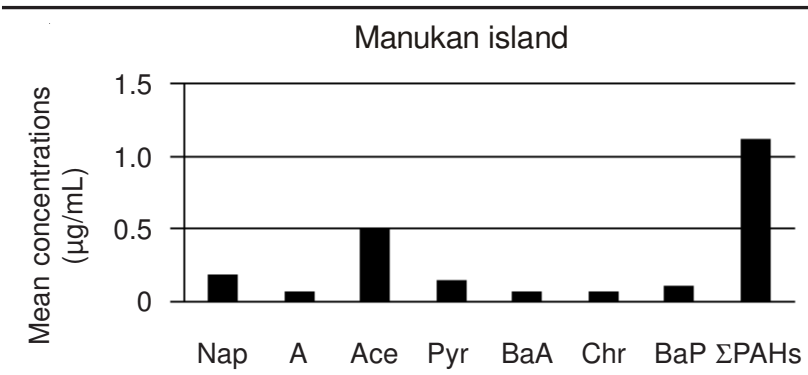

PAH compounds

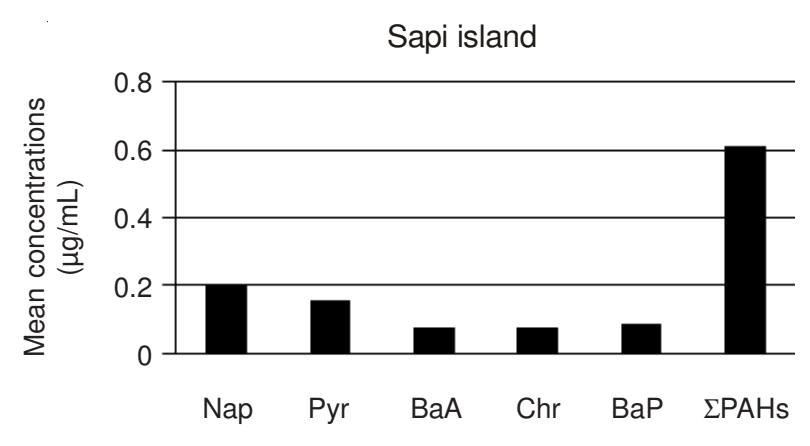

PAH compounds

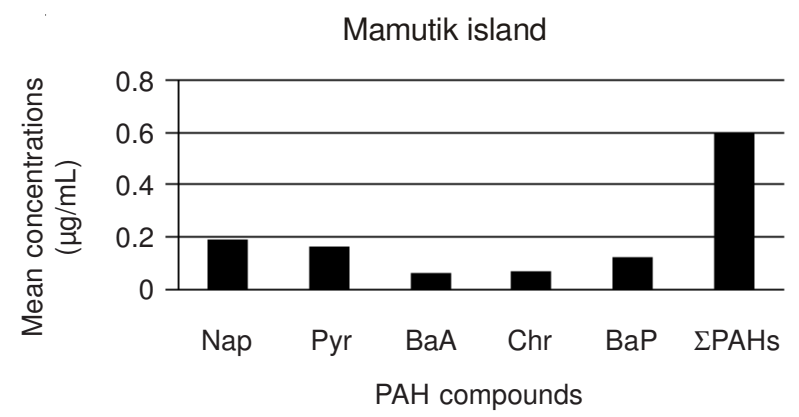

Fig. 4. Polycyclic aromatic hydrocarbons concentrations in water samples collected in three small islands (Manukan, Sapi and Mamutik Islands) during December sampling

genic and potential cancer causing agent in humans. Other than water samples, sediment samples from the islands were also collected and analyzed.

Reviewing at the sediments analysis data, results show that most of the polycyclic aromatic hydrocarbons were not detected or below detection limits. Only small amounts of Acenapthane was detected in all three sample locations measuring at $0.02 \mu \mathrm{g} / \mathrm{mg}$ in Mamutik and Sapi and $0.04 \mu \mathrm{g} / \mathrm{mg}$ and Manukan. Other readings were too low which is below the reporting limits and can be reported as $<0.02 \mu \mathrm{g} / \mathrm{mg}$. This preliminary study suggests that the occurrence on polycyclic aromatic hydrocarbons originated from recent contamination and not from accumulated sources. Abdullah et $a l .{ }^{24}$ reported that the presence of polycyclic aromatic hydrocarbons is low in sandy soil sediments. These results were comparable with the result of second sampling during low tide.

Comparison of data obtained during different sampling periods: Comparing the data obtained during low tide and hot weather conditions, it was found that the contamination level of polycyclic aromatic hydrocarbons in the water follows similar pattern as in February. In Manukan the first sampling showed the presence of seven polycyclic aromatic hydrocarbon compounds with total polycyclic aromatic hydrocarbons ( $\mathrm{PAH}$ ) of $1.12 \mu \mathrm{g} / \mathrm{mL}$, compared to only five compounds (pyrene, benzo(a)anthracene, chrysene, benzo(a)pyrene and traces of some amounts of naphthalene) in the second sampling. The total polycyclic aromatic hydrocarbons ( $\Sigma$ PAHs) seems to be less $(0.63 \mu \mathrm{g} / \mathrm{mL})$ in February, almost half of the amount detected in December. Water related activities such as boating but speedboat activities were observed during December sampling and similar activity was not observed in Manukan during the February sampling. This suggests that no recent input of polycyclic aromatic hydrocarbons originated from the boating activities. It also indicates that the level of polycyclic aromatic hydrocarbons is greatly influenced by the local activity and not from other sources. The $\Sigma$ polycyclic aromatic hydrocarbons detected in Sapi and Mamutik during the second sampling are $0.61 \mu \mathrm{g} / \mathrm{mL}$ and $0.63 \mu \mathrm{g} / \mathrm{mL}$ respectively, somewhere similar to the concentrations reported in previous sampling.

Similar results were observed regardless on the effect of high tide and low tide in the water during sampling. This might be influenced by resent rainfall and fast flushing effect that would transfer the pollutants to other places. Thereby reducing the influence on the dispersal of contaminants during sampling. According to the meteorological data obtained by the Meteorological Department, Kota Kinabalu reported that the mean wind velocity on the previous and the day of sampling in December are $1.8 \mathrm{~m} / \mathrm{s}$ and $1.7 \mathrm{~m} / \mathrm{s}$. similar to the wind velocity on February which was reported at $1.6 \mathrm{~m} / \mathrm{s}$ and $1.7 \mathrm{~m} / \mathrm{s}$. Other then the similar wind speed, similar temperature and rainfall during one day prior to sampling date were also recorded to be almost similar. This explains on the possibility of similarity in the obtained contaminant reading. Although similar contamination and polycyclic aromatic hydrocarbons were found in water samples, total different pattern of polycyclic aromatic hydrocarbons contamination was recorded in the sediment samples. Relatively higher levels of polycyclic aromatic hydrocarbon contamination were detected during the second sampling. In Sapi Island total polycyclic aromatic hydrocarbons detected to was $1.18 \mu \mathrm{g} / \mathrm{mg}$, whereas higher reading of total polycyclic aromatic hydrocarbons was observed in Mamutik which is $1.63 \mu \mathrm{g} / \mathrm{mg}$. Highest level of Total polycyclic aromatic hydrocarbons were observed in Manukan, the busiest island compared to the rest of the two islands, Total polycyclic aromatic hydrocarbons reading was $3.31 \mu \mathrm{g} / \mathrm{mg}$. Manukan Island is very famous for its water sports activity. Low polycyclic aromatic hydrocarbons concentrations in the water showed that there were no recent input or dispersed input and the sedimentation analysis showed the accumulated occurrence of polycyclic aromatic hydrocarbons were not severe in these islands. This supports the suggestion from Pruell's assessment on 1986 concerning the slow release of polycyclic aromatic hydrocarbons from sediments ${ }^{39,40}$. Levels of hydrocarbons in seawater tend to fluctuate throughout the year as reported by Abdullah et $a l .{ }^{24}$. Sediments containing fine particles tend to be good accumulators of organic pollutants, presumably because of their greater effective surface area ${ }^{38,41}$. Coarse-grained sands and sediments made up of stones or shell on the other hand, 
reduce the hydrocarbon content, even though the corresponding levels in vicinity seawater might be high. All samples in this present study were collected from coarse-grained sands as well as sands and shell, hence the corresponding level of polycyclic aromatic hydrocarbons in sediment was relatively low similar to results by Abdullah et al. ${ }^{24}$.

The dominant polycyclic aromatic hydrocarbons found in sediment sample are naphthalene, fluorene, fluoranthene, pyrene, benzo(a)anthracenee, chrysene, benzo (b) fluoranthene and benzo (a) pyrene. Respectively, two to three rings polycyclic aromatic hydrocarbon (defined as $128<\mathrm{m} / z>192$ ) dominate in these samples, along with four to six membered rings polycyclic aromatic hydrocarbon (defined as $202<m / z>292$ ). Total concentrations of potentially carcinogenic polycyclic aromatic hydrocarbons ( $\Sigma \mathrm{CPAH})$, which include benzo(a) anthracene, benzo(b)fluoranthene and benzo(a)pyrene varied from $0.3 \mu \mathrm{g} / \mathrm{mg}$ in Mamutik, $0.41 \mu \mathrm{g} / \mathrm{mg}$ in Sapi Island and $0.53 \mu \mathrm{g} / \mathrm{mg}$ in Manukan Island. The influence of boating activity amongst anthropogenic sources on sediment polycyclic aromatic hydrocarbons pollution was quite clear.

Young $^{19}$, found that fluranthene occurs widely in the environment. The available limit fixed is for drinking water, European community maximum acceptable concentration of $200 \mathrm{ng} / \mathrm{L}^{19}$. Fluoranthene is of low acute oral toxicity but no data are available on its chronic or reproductive toxicity. It is a potent mutant in bacterial and many mammalian in vitro test systems, but only in the presence of metabolic activation ${ }^{19}$. However limited evidence from short-term in vivo cytogenetic and long term skin penetrating carcinogenicity studies in rodents indicates that fluoranthene is not carcinogenic. There is some evidence that fluoranthene may enhance the carcinogenicity of benzo(a)pyrene but the relevance on relation to environmental exposure and human health is unclear. Fluoranthene is found in many combustion products. Its presence is an indicator of less efficient or lower-temperature combustions ${ }^{42}$. While benzo(a)pyrene is an indication that samples were exposed to solar radiation, others sources include from automobile exhaust fumes especially diesel engines ${ }^{9,37}$.

This polycyclic aromatic hydrocarbon distribution is in good agreement with a petrogenic origin (combustion residues of fossil compounds such as gasoline, kerosene, gas oil) ${ }^{43}$. Finally, it was considered that ratio NAP/PHE is more one the presence of fresh and un-weathered petroleum was assumed ${ }^{44}$. In this study, NAPH/PHEN ratios ranged from 4.4 to 6 in Manukan and Sapi Island, suggesting petrogenic sources for polycyclic aromatic hydrocarbons in these sites. However further monitoring and evidence is needed to support petrogenic input prediction. The polycyclic aromatic hydrocarbon group profile shows the predominance of two to three membered rings polycyclic aromatic hydrocarbons in water samples while four and six membered rings polycyclic aromatic hydrocarbons dominated in sediments samples. Similar to research conducted by Abbas and Brack in 2005, on the water clarity and influence of anthropogenic sources by weather conditions, soil properties or easy degradation of polycyclic aromatic hydrocarbons in soil.

Ratios between pairs of individual polycyclic aromatic hydrocarbons have often been employed as a method of determining the most significant sources of polycyclic aromatic hydrocarbons detected in environmental samples. In order to characterize polycyclic aromatic hydrocarbons with respect to specific source, Budzinki et al. ${ }^{45}$ have applied a diagnostic elemental ratio. Yang et $a l .{ }^{46}$, reported a ratio of 3 for PHE/ ANT, which indicate polycyclic aromatic hydrocarbons rising from motor vehicle exhaust, whereas a ratio of over 50 implies major source originate from mineral oil. In this study the PHE/ANT is 7.5 in Manukan Island and 5 in Sapi island. Similarly, a ratio of 1 for FLT/PYR indicated polycyclic aromatic hydrocarbon to be from combustion process and ratio of more then one suggest of suggested origin to be petroleum derived as found in Mamutik and Manukan Island ${ }^{47,43}$. Also $\mathrm{BaA} / \mathrm{BaP}$ of 1 and $\mathrm{BaP} / \mathrm{BPE}$ of 0.2 to 0.5 were indicative of vehicle exhaust emission while $\mathrm{BaP} / \mathrm{BPE}$ greater than one was indicative of coal combustion. In this study the $\mathrm{BaA} / \mathrm{BaP}$ are 0.7 in Mamutik, 0.5 in Manukan and 0.9 in December, 0.6 in February for Sapi Island. This again suggests the sources from automobile source. The PYR/BaP ratio of less than one to 50 implied that the major source was diesel powered vehicle as indicated in all the small islands ${ }^{48,49}$.

Determination and identification of polycyclic aromatic hydrocarbons compounds in Port Kota Kinabalu: Water samples from the port for both December and February sampling are presented in Fig. 5. Low amount of total polycyclic aromatic hydrocarbons were detected to be present during both sampling times, at $0.53 \mu \mathrm{g} / \mathrm{mL}$ and $0.51 \mu \mathrm{g} / \mathrm{mL}$ respectively in December and February. Although several low molecular weight polycyclic aromatic hydrocarbons were detected, the concentrations were very low and considered not significant. Only PYR and BaP were detected with concentrations close to $0.1 \mu \mathrm{g} / \mathrm{mL}$ during both analysis. Looking at the very low concentrations of LPAHs in this location, it is safe to report that the level of polycyclic aromatic hydrocarbons contamination in this station is at very low level.

Hydrocarbons in water and sediment from Malaysian waters have been determined and catalogued in previous surveys by Phang et al..$^{50}$, Law et al., etc ${ }^{41}$. Although the surveys largely focused on areas connected with the exploration of oil and gas reserves, several isolated studies have been conducted along the west coast Peninsular Malaysia. Phang et al. ${ }^{50}$ reported that the levels of hydrocarbons in the range of 0.05 to $0.12 \mathrm{mg} / \mathrm{L}$ in Penang Island and 21.7 to $74.5 \mathrm{mg} / \mathrm{kg}$ in sediment samples. Surveys in offshore waters off Sarawak in East Malaysia recorded concentrations in range of 0.013 to $0.545 \mathrm{mg} / \mathrm{L}$ and $7.42-1089 \mathrm{mg} / \mathrm{kg}$ for water and sediment samples ${ }^{51}$. Hence the polycyclic aromatic hydrocarbons levels measure in the present study appears to be in very low level, compared to other studied locations in Peninsular Malaysia. The level of hydrocarbon content in seawater is higher nearcoastal waters rather than in open $\mathrm{sea}^{24}$. According to the Food and Agricultural Organization ${ }^{52}$, (FAO, 1982), seawater containing hydrocarbon levels less than $0.0025 \mathrm{mg} / \mathrm{L}$ can be classified as unpolluted. Unpolluted coastal sediments on the other hand, contain hydrocarbons less than $100 \mathrm{mg} / \mathrm{kg}$. On these basis and also when compared to the levels in marine water and sediments reported elsewhere in the world comparable in terms of shipping activities, the level detected in this study clearly shows that the coastal waters and sediments from the study sites are in low levels (Fig. 6). 


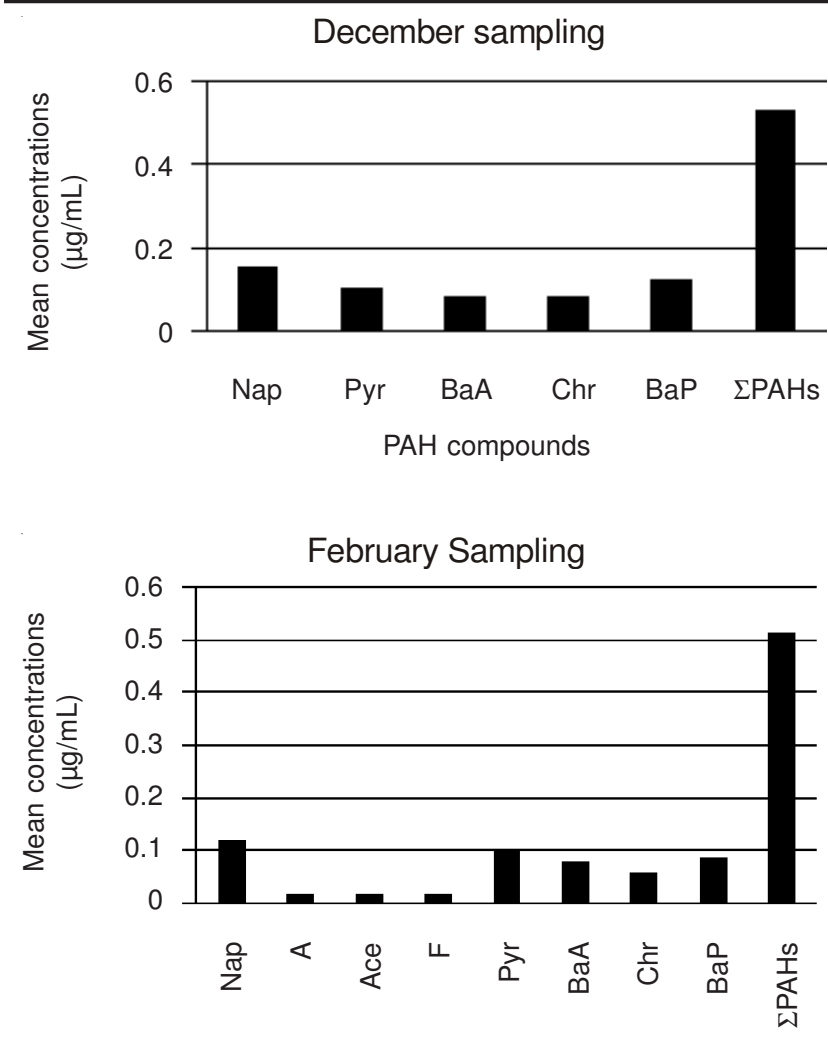

PAH compounds

Fig. 5. Determination and identification of polycyclic aromatic hydrocarbon compounds from water samples in KK Port

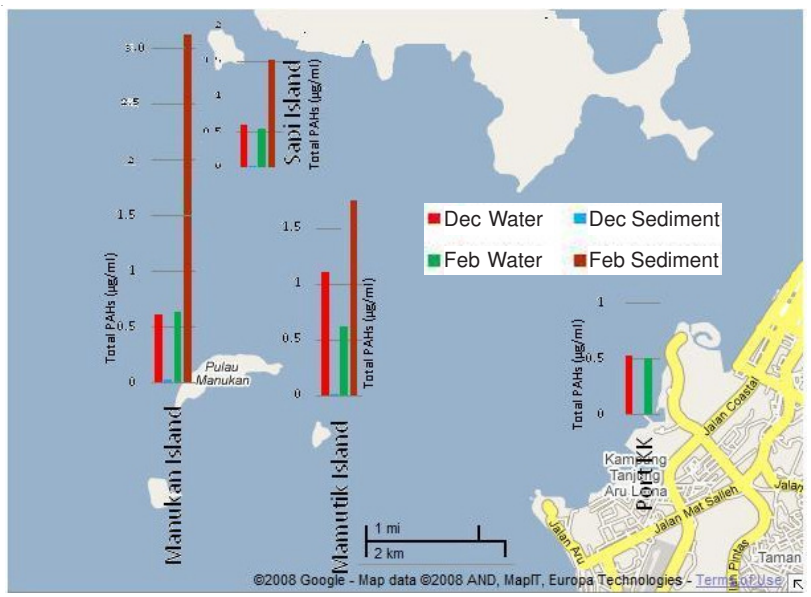

Fig. 6. Summary of total polycyclic aromatic hydrocarbons in all monitored stations

There are two main differences in the polycyclic aromatic hydrocarbon distributions during high tide and low tide, especially the concentration and distributions in the sediments. Sediments composed of high clay and silt will contain potentially more oil or hydrocarbon than sandy sediment as is the case in this research area, explains the low readings obtained ${ }^{53}$. It is realized that preliminary investigation needs to be developed further, including many more measurement in locations representing other activities. It is also probable that the chemistry of polycyclic aromatic hydrocarbons in tropical waters, where the ambient temperature and relative humidity are higher coupled with abundant sunshine, may differ from that of temperate regions. This study clearly shows that quantitative determination of hydrocarbon is not sufficient enough to assess the exact degree of petroleum contamination in waters and sediments. Moreover this study managed to identify the level of hydrocarbon is associated to petroleum contamination from petrogenic origin. As reported by Zakaria et al ${ }^{54}$, polycyclic aromatic hydrocarbons provides useful additional information in source identification of petroleum pollution, as a potent tool for source- identification of petroleum pollution.

\section{Conclusion}

The concentrations of detected oil and grease contamination are influence by several factors depending on the type, quantity and weathered state of the oil and the prevailing climatic and tidal condition. All the reading obtained did not meet the water quality standard for oil and grease by the Malaysian: interim water quality standard. Quantitative and qualitative analyses of polycyclic aromatic hydrocarbons molecular markers identification on tropical coastal waters and sediments of Sabah, lead to six groups of stations distinguished according to main origins of hydrocarbon which are all from petroleum sources. However none observed to be derived from pyrolitic, terrestrial or digenetic sources. The overall levels of anthropogenic polycyclic aromatic hydrocarbons are low compared to relevant areas in Peninsular Malaysia or other areas worldwide and reveal a low level of polycyclic aromatic hydrocarbons pollution.

\section{ACKNOWLEDGEMENTS}

This research was supported by the Center of Research \& Innovation, University Malaysia Sabah (Grant No.FRG0203SG-1/2010) and is gratefully acknowledged. The author would also like to thank Dr Steve Hensen, En Imran, Mr Mohan, Mrs Anitha and all team members of Anametrics (M) Sdn. Bhd,Shah Alam for assistance with the polycyclic aromatic hydrocarbons analysis. Special thanks to Ms Nurulain Rahmat and Ms Khuneswari Gopal Pillay for their enormous help during sampling and analysis.

\section{REFERENCES}

1. D. Thomas, Principles of Water Quality. Academy Press Inc. Florida (1984).

2. S. Payal, Annual Edition Environment 02/03. L.A. John, McGrawHill Publications. United States, edn. 21 (2002).

3. K. Ravindra, E. Wauters and R. Van Grieken, Sci. Total Environ., 396, 100 (2008).

4. Y. Wang, P.-H. Li, H.-L. Li, X.-H. Liu and W.-X. Wang, Atmos. Res.. 95, 1 (2010)

5. I. William, Environmental Chemistry, John Wiley \& Sons, U.K. (2001).

6. W. Stumm, Chemistry of the Solid-Water Interface; Process at the Mineral Water and Particle-Water Interface in Natural System, John Wiley \& Sons, New York (1992).

7. International Agency for Research on Canser (IARC), Polynuclear Aromatic Compounds, Part 1; Chemical, Environmental and Experimental Data, 32 (95-129) (1983).

8. A. Negri, K. Burns, S. Boyle, D. Brinkman and N. Webster, Environ. Pollut., 143, 456 (2006).

9. C.D. Simpson, W.R. Cullen, T.Y.T He, M. Ikonomou and K.J. Reimer, Chemosphere, 49, 315 (2002).

10. United States Environmental Protection Agency (USEPA), 1995. Method 1664; N-Hexane Extractable Material (HEM) and Silica Gel Treated N-Hexane Extractable Material (SGT-HEM) by Extraction and Gravimetry (Oil and Grease and Total petroleum Hydrocarbons). EPA821-B-94-004b, April 1995. www.doe.gov.my, 29/09/2007. 
11. A.D. Geiselbrecht, R.P. Herwig, J.W. Deming and J.T. Stanley, Appl. Environ. Microbiol., 62, 3344 (1996).

12. United States Environmental Protection Agency (USEPA), Test plan for Tall Oil and Related Substances. May (2001).

13. J.M. Rebecca, E.A. Sabine and B.H. Barbara, Appl. Environ. Microbiol., 68, 2858 (2002).

14. P. O'neil, Environmental Chemistry, Chapman and Hall, London, edn 2 (1993)

15. W.K. Chung and G.M. King, Appl. Environ. Microbiol., 67, 5585 (2001).

16. R.B.J. Peachey, Marine Pollut. Bull., 46, 1365 (2003).

17. A. Masih and A. Taneja, Chemosphere, 65, 449 (2006)

18. K.K. Lie, S. Meier and P.A. Olsvok, Comp. Biochem. Physiol. Part C: Toxicol. Pharmacol., 150, 141 (2009).

19. W. Young, Fluranthene in Drinking Water and its Effects on Human Health. Foundation for Water Research.Report No FR0276 (1992).

20. The International Agency for Research on Cancer (IARC), IARC Monographs on the Evaluation of the Carcinogenic Risk of Chemicals to Humans; Polynuclear Aromatic Compounds, Chemical, Environment and Experimental Data, Part 1, 32 (1998).

21. Wei Wang, Min-Juan Huang, Yuan Kang, Hong-Sheng Wang, Anna O.W. Lung, Kwai Ching Cheung and Ming Hung Wong, Sci. The Total Environ. (2011) (in Press).

22. F. Yazdanparasr, Nouri and A. Rabbani, Int. J. Environ. Sci. Technol., 1, 215 (2004).

23. Michael Wong, Sipadan Borneo's Underwater Paradise.Odyssey Publishing. Singapore (1991).

24. A.R. Abdullah, N.M. Tahir and L.K. Wei, Bull. Environ. Contaminat. Toxicol., 53, 618 (1994).

25. T. Isobe, H. Takada, M. Kanai, S. Tsutsumi, K.O. Isobe, R. Boonyatumanond and M.P. Zakaria, Environ. Monit. Assess., 135, 423 (2007).

26. F. Jakobsen, N. Hartstein, J. Franchisse and T. Golingi, Ocean Coastal Manage, 50, 84 (2007).

27. D. Cataldo, J.C. Colombo, D. Boltovskoy, C. Bilos and P. Landoni, Environ. Pollut., 112, 379 (2001)

28. N.F.Y. Tam, Y.W. Teressa and Y.S. Wong, Marine Pollut. Bull., 51, 1092 (2005).

29. C.L. Gou, H.W. Zhou, Y.S. Wong and N.F.Y. Tam, Marine Pollut. Bull., 51, 1054 (2005)

30. Environmental Protection Agency, Environmental Protection Agency, Methods for Chemical Analysis of Water and Wastes, 3rd Ed. Environmental Protection Agency, Environmental Monitoring System Laboratory-Cincinnati (EMSL-Ci), Cincinnati, Ohio. EPA-600/4-79-020, Method 413.1 (1983).

31. American Public Health Association, Standard Methods for the Examination of Water and Wastewater, 18th Ed. APHA. Washington. Method 5520B and Method 5520F (1992).

32. American Chemical Society, Safety in Academic Chemistry Laboratoties, 3rd Ed. Committee on Chemical Safety (1979).
33. Liu Ying, Ling Chen, Qing-hui Huang, Wei-Ying Li, Yin-Jian Tang and Jian-Fu Zhao, Sci. Total Environ., 407, 2931 (2009).

34. K.A. Burns and S. Codi, Mangrove and Salt Marshes, 2, 63 (1998).

35. Jabatan Alam Sekitar, Malaysia Marine Oil Spills. JAS, Sabah (2007).

36. F.Y. Nora, T. Tam, W.Y. Wong and Y.S. Wong, Marine Pollut. Bull., 51, 1092 (2005).

37. M. Zheng, M. Fang, F. Wang and K.L. To, Atmosph. Chem., 34, 2691 (2000).

38. K.A. Burns, J.P. Villanueve, V.C. Anderlini and S.W. Fowler, Marine Pollut. Bull., 13, 240 (1982).

39. J.M. Ayotamuno, R.N. Okparanma and F. Amadi, Afr. J. Environ. Sci. Technol., 54, 262 (2006).

40. R. D'Adamo, S. Pelosi, P. Trotta and G. Sansone, Bioaccumulation and Biomagnifications of Polycyclic Aromatic Hydrocarbons in Aquatic Organisms. Department of Environment, Ministry of Natural Resources and Environment Malaysia (1997).

41. A.T. Law, N.A. Shazili, R. Yaacob, L.H. Chark, M.N. Saadon and L. Shamsuddin, Coastal oceanographic studies in the Straits if Malacca and South Cjina Sea: In port Dickson coastal waters. Conference on the intensification of research in priority areas,Deceber 1991. Penang, Malaysia, p. 12 (1991).

42. Y.M.J. Nasr, Omar, Tan Chin Mon, N.A. Rahman and A. Radzi, Sci. Total Environ., 369, 76 (2006).

43. G. Mille, M. Guiliano, L. Asia, L. Malleret and N. Jalaluddin, Chemosphere, 64, 1062 (2006).

44. S. Dahle, V. Savinov, G. Matishov, A. Evenset and K. Naes, Sci. Total Environ., 306, 57 (2003).

45. H. Budzinki, I. Jones, J. Bellocq, C. Pierand and P. Garrigue, Mar. Vhem., 58, 85 (1997)

46. S.S. Yang, H.L. Chang, and C.B. Wei, J. Biomass Energy Soc. China, 10, 147 (1991).

47. M.B. Yunker, S.M. Backus, E.G. Pannatier, D.S. Jeffries, R.W. Macdonald, Estuary Coast Shelf Sci., 55, 1 (2002).

48. A.A. Olajire and W. Brack, Sci. Total Environ., 340, 123 (2005).

49. N.Y. Omar, R. Abas, K.A. Ketuly and N.M. Tahir, Atmos. Environ., 36, 247 (2002)

50. S. Phang, T.K. Hwang and T.T. Ang, Hydrocarbon Content in the Coastal Water Along the East Coast of Peninsular Malaysia. Coastal Resources of East Coast Peninsular Malaysia, An Assessment in Relation to Potential Oil Spills. University Sains Malaysia Publication (1984).

51. A.T. Law and S. Libi, Occational Publications, 4, 53 (1988).

52. Food and Agricultural Organization (FAO), The review of the health of the oceans. FAO/ IMCO/ Unesco/ WMO/ IAEA/ Unep Joint Group of Experts on Scientific Aspects of Marine Pollution (Gesamp). Rep Stud Gesamp, 15, 108 (1982)

53. A. Pauzi, Environ. Monit. Assess., 44, 443 (1997).

54. M.P. Zakaria, T. Okuda and H. Takada, Marine Pollut. Bull., 42, 1357 (2007) 